\title{
The Moderating Effect of Organisational Culture on the Relationship Between Workplace Learning and Employees' Performances in the United Arab Emirates
}

\author{
Faisal Ahmed Ali Al-Hammadi \\ Ahmad Amri Zainal Adnan \\ Siti Asma' binti Mohd Rosdi
}

\section{Abstract}

The purpose of the current study was to elaborate the moderating effect of culture on workplace learning and employees' performances in the United Arab Emirates. The study had a purpose to contribute new knowledge to the existing literature available on the workplace learning and job performances. It also highlighted the contemporary literature on the topic specifically formal and information learning, as well as, performance related to tasks and contextual. The research explained and highlighted the role of training and development on employees' performances to improve the quality of task process. An empirical study was conducted and data was collected through questionnaire to obtain the results. The present study aimed to contribute to new knowledge to the existing literature on workplace learning and job performance. Particularly, the study analysed contemporary literature on workplace learning and job performances, specifically formal and informal learning as well as employee task performance and contextual performance. The study hypothesized that informal, incidental and formal workplace learning had direct positive significant relationships with employee task and contextual performance. Findings of the study developed that adopting effective techniques of workplace learning, and techniques can improve employees' performances. The study, further, showed that the Informal, formal and incidental workplace learning had direct and positive impact on employee task and contextual performance. The study showed that there is a significant positive relationship between workplace learning including formal, informal and incidental learning, and job performance including task performance, contextual performance and counterproductive work behaviour. It was also found that there was a positive relationship between result-oriented cultures with two types of job performance but there was a significant relationship between team orient culture and task performance. Furthermore, the moderating effect of innovation, communication and people-oriented culture on the relationship between incidental workplace learning and contextual performance was significant.

Keywords: Workplace learning, informal workplace learning, incidental workplace learning, task performance, contextual performance, counterproductive work behaviour, organisational culture 


\section{Introduction}

The employees are considered as the backbone of any profitable business organisations. How an organisation successfully achieves its goals depends on the performance of employees. Organisations have accepted the fact that in order to achieve sustainable development, human resource can be considered as a major source (Aragon-Sanchez et al., 2003; Park, 2009). Employees are the most important and valuable assets in organisations. They are not only responsible for making organisations reputable in the competitive market, but also have greater impact on profitability. On the other hand, if employees are not properly trained, they will be unable to understand and develop skill set that is important for the accomplishment of tasks. Employees who obtain proper learning opportunities perform the best on their jobs. They are highly motivated and likely to keep their job for longer time period than those employees who do not have opportunities to get learning (Jiménez-Jiménez \& Sanz-Valle, 2011). Learning in terms of human resource development shows that the learning is the only effective way to develop human resources within the organisation. The competitive business environment in the $21^{\text {st }}$ century requires the companies to gain competitive advantages and achieve success with that advantages. Workplace learning can be used as an effective tool by managers to gain competitive advantages in the current highly competitive business environment (Cromwell \& Kolb, 2004; Heilmann, 2007; Rothwell, 2002).

Workplace learning has three main elements including; formal learning, Informal learning and incidental teaching (Park, 2009). Workplace learning is considered as the process of providing opportunities to learn effective skills, information and communication methods, and workplace education that is significantly important to accomplish the work related tasks and also provide workplace and professional development opportunities to employees (Shuck, Ghosh, Zigarmi, \& Nimon, 2013). In the current business environment, it is important to gain competitive advantages for sustainable market development and the capabilities, competencies, and skills of the employees have been considered as major method of gaining competitive advantages (Meyer \& Allen, 1991). In order to develop the required knowledge, abilities and skills of workforce to perform well on the job requires efficient and effective learning opportunities. These opportunities also enhance employees' motivation and commitment to the work. The training and workplace learning depend on the actual nature of work to be performed by employees; organisations plan proper trainings in order to optimize growth and development of employees. Many organisations implement by putting resources in developing the skills for employees and empower employees to accept uncertain conditions (Bednall, Sanders \& Runhaar, 2014). On the other hand, employees put their efforts and loyalty by fully participating in activities of organisations in such learning programs. The employees fully apply best knowledge and skills to achieve organisational strategic goals (Pajo, Coetzer, \& Guenole, 2010). Learning is not only important from organisational point of view, but also from individual point of view that are deciding up organisation (Colarelli \& Montei, 1996; Becker, 1993). It means that the workplace learning not only increase employees' job-related knowledge and providing knowledge about the market trends, but also give employees to clarify the organisational objectives and strategic goals. Nowadays, organisations have changed with advanced technology and flexible working environment with knowledge people may embrace. According to Lin (2008), it is necessary for employees to continuously update skills, expertise and knowledge on regular and continuous basis.

Performance of the employees at workplace is referred as successful completion of tasks with efficiency and effectiveness. In any firm, trainings, workshops and learning opportunities are 
provided at different levels of management to increase the performance of the organisational processes and individual performances. The level of coordination with the above mentioned process can provide strategic and competitive advantage to the organisation. In fact, the organisation looking to enhance competitive advantage actually understands the importance of workplace learning and its link for improving the job performance of the employees (Cromwell \& Kolb, 2004). Research done in this area gives evidence that organisations that provide workplace learning options have positive impact on the performance of both employees and the organisation (Rothwell, 2002; Cromwell and Kolb, 2004; Heilmann, 2007). Organisations are rapidly facing new challenges and tough competitions at global level. In order to cope with these challenges, organisations need to design proper programs of learning skills from time to time (Tai, 2006). Learning programs will help organisations to provide improved learning atmosphere among employees and to give them skills to successfully cope with challenging situations (Jones, Woods \& Guillaume, 2016). Organisational cultures can also have different dimensions in terms of power culture, role culture and hierarchy culture. Power, information system within organisation and flow can have an impact on the organisational hierarchy and systems. These are the aspects of power culture, hierarchy culture and role culture. In a power culture, leaders can make rapid decision and they control the strategy of decision making. But the power culture requires a strong deference to leaders who are in charge of organisations. The role culture can be seen when the functional culture is created, where employees within an organisation know their jobs, reports to their superiors and value accuracy and efficiency above all. The hierarchy culture is considered same as the role culture, in which the system is highly structured. The focus is on doing things right, with efficiency and being stable. Employees working within the organisation need to be committed towards the collective objectives as part of the task cultures and clan cultures. In case of task cultures, the team members need to be expert in order to solve organisational problems. A matrix is developed in case of these type of cultures. It is due to the fact that task is important and the number of small teams are in play. In clan culture, employees work like a family with focus on mentoring doing things together and nurturing. The organisational culture has links with employees' performances and productivity. A right culture can be developed with proper managerial intention and leadership role.

\begin{tabular}{|l|}
\hline Moderating effects: \\
Organizational culture \\
Innovation culture \\
People-oriented culture \\
Communication \\
Result-oriented culture \\
Team culture
\end{tabular}




\begin{tabular}{|l|l|l|}
\hline Independent variables: & & Dependent variables: \\
Workplace learning & Employees' performances \\
Formal learning & Task performance \\
Informal learning & Contextual performance \\
Incidental learning & Counterproductive work behavior \\
\cline { 2 - 3 } & &
\end{tabular}

Theoretical framework of research

\section{Literature Review}

\section{Workplace learning:}

The concept of workplace learning has been defined in many studies according to different perspectives. Generally, it is considered in perspectives of workforce capability enhancement. Nadler (1970) defined that the workplace learning is considered as an important element of human resource development model (HRDM). They also concluded that human resource development is a system which comprised of all those activities that help to add worth of workforce in an organization. It also helps in bringing the behavioral reforms with the help of learning programs. In this regard, trainings are considered as an important element for workplace learning. Jacobs and Park's (2009) defined workplace learning as a process of different educational and learning programs that are related with work accomplishment. According to Cairns and Malloch (2011), workplace learning is a different concept in organizations from classroom-based learning. Workplace learning is a collaborative process which occurs in the social context (Brown \& Duguid, 1991). Workplace learning is a process through which individuals, organizations and teams are provided opportunities to learn skills, acquire knowledge and adopt attitudes with the help of continuous interaction within an organization and within teams to solve business problems and to improve performances (Moon \& Na, 2009). Many studies have taken workplace learning as a formal learning process during job by an employee (Farouk, Abu Elanain, Obeidat \& Al-Nahyan, 2016; Wilkins, 2001) but other aspects of the workplace learning are still to be explored within the context of employees' performances. Other dimensions of the workplace learning are formal learning, incidental learning and informal learning (Daryoush, Silong, Omar \& Othman, 2013; Marsick \& Watkins, 2015). Formal learning, as the name depicts, is a type of learning process which is supported and provided by the management of organizations (it is pre-planned). Management of organizations is responsible to determine learning process in case of formal learning. In contrary to that, unstructured and non-institutional types of workplace learning are known as informal learning and it normally occurs through daily routines of employees. In case of informal learning, employees have options to make choices in the learning processes as per their personal interests, preferences and personal characteristics (Marsick \& Volpe, 1999).

\section{Employees' performances}

The ultimate goal of a business is to improve performances which helps in achievement of retaining and acquiring of talented pool as well as to attain the market leadership. Job performances can be defined as activities and human behaviors which are directly or indirectly linked with organizational goals and aims (Motowildo, Borman, \& Schmit, 1997). Employees' performances are not consequences or results of an action, rather it is described 
as a direct action or behaviour (Campbell, McCloy, Oppler, \& Sager, 1993). There are two main concepts involved in defining employees' performances given by Gilber (1978). According to him, the term performance means individual development of employee and effectiveness of the whole system. The second concept involved here is the behavioural concept. According to behavioural concept, the changing system focused on work of individual employees but little consideration should be paid to his attitude (Gilbert, 1978). Previous studies considered employee's performances as a result of human behaviour not an independent factor which contributes to organizational goals. Organizations can improve job performances of employees if they have control over their behaviours (Barrie and Pace, 1998). Considering these definitions, a more comprehensive definition is provided by Jones (2006) that while assessing the performance of an employee his/her attitude and behaviour both should be considered as both are important characteristics of employee's personality. There are different dimensions of employees' performances that have been discussed in the previous literature. For an example, Campbell et al. (1990), identified eight factors of a job performance model which are applicable in almost all types of jobs. Task performance is related to a technical side of a job which involves effort of employees to complete a task. The second broad category is the contextual performance which does not relate to the technical knowhow of any job. Borman and Motowidlo (1993) defined two broad categories of performance: task performance and contextual performance. The first category is related to providing products or services with expertise and later category is about activities which help to support the technical part of a job and are called contextual performance: coordination, planning, etc. The definition of task performance covers activities that are carried out to contribute to an organization's technical functions either directly or indirectly (Borman \& Motowidlo, 1993). All other activities which are not covered under the definition of task performance are called contextual performance: facilitating peer and team performance (Campbell, et al., 1990; Van Dyne \& LePine, 1998), defending, supporting, and endorsing organizations' objectives (Borman \& Motowidlo, 1993) interpersonal communications (Murphy \& Shiarella, 1997), courtesy and civic virtue defined by Dennis (1988), spreading goodwill by George and Brief (1992). In contrary to these two positive aspects of an employee's performance, there is one negative measure attached to the performance of the employees which is called counter productive work behaviour (CWB). Counterproductive work behaviour is negative trait which hampers the performances of employees.

\section{Organizational culture}

There are many dimensions of organizational culture which could affect the relationship between workplace learning and employees' performances. This is because of the variability of the dimensions of the culture in an organization. This variability could be considered into the research to find the real term effects of the actual and predicting variables. According to the findings of Watkins and Marsick (2003), culture of an organization can be considered as a foundational context in the process of transforming the workplace learning into employee's personal performance. A learning culture of an organization may affect different areas of job requirements which include behaviour of leaders and organizational performances. So, it is imperative to study the impact of organizational culture not only to judge the performance of the employees, but also in context achievement of organizational goals (Joo, 2012). Learning is an important element to improve employees' performances, but transfering of learning into the behavioural changes depends on many other factors. One of these factors is the cultural that influences the relationship between workplace learning and job performance of an 
employee. Different dimensions of culture are discussed in literature: team oriented culture, stability culture, result oriented culture, innovation oriented culture, people oriented culture and communication oriented culture. Organizational culture is considered as a set of shared values and beliefs by employees of an organization which directly or indirectly influences the behaviours (Schein, 1990). The most common model of culture is suggested by O'Reilly III et al. (1991). There are different dimensions suggested by them. O'Reilly, Chatman \& Caldwell (1991) have developed a model which is based on the point that an organization's culture can be easily distinguished from the values and beliefs which are reinforced in organizations. The name which is given to their model of cultural dimensions is known as organizational cultural profile (OCP). This is considered as a self-reporting mechanism which can easily distinguish among different categories of culture. Employees' values are also measured in terms of organizational values to make predictions regarding employees' behaviours and intensions. OCP is also used as a tool to measure employees' commitments with the job (O'Reilly III et al., 1991). According to team oriented culture, it is better to make your teamwork as core competency of a company, emphasize on self-managing teams which are empowered enough to make their decisions by themselves (O'Reilly III et al., 1991). The emphasis of result oriented culture is on setting targets and goals then find suitable people who could support the achievement of these goals and results (Denison, 1990). In the case of innovation culture, the focus point revolves around the leadership of an organization. Leadership plays an important role in encouraging and cultivating innovative environment in an organization. In case of stable culture, the culture is more predictable, bureaucratic and rules oriented. Quick actions cannot be taken in such kind of organizations which are following this culture type (O'Reilly III et al., 1991). In people oriented culture, organizations mostly follow the following characteristics: good work is rewarded, employees are valuable partners, investment in employees results in success and growth, people are considered as people not just employees and service is the key to success (O'Reilly III et al., 1991). Communication culture is a type of culture where organizations encourage open communication and employees' involvement in decision making of companies. It is defined as shared values, attitudes, customs, and beliefs, written or unwritten rules within organizations (Schein, 1990). So, organizational culture took too much time to develop and to be considered as valid.

\section{Research Methodology}

The current study was based on the concept of empirical research methods and developing quantitative measures to develop the effect of workplace learning on performance of employees. The current research dealt with the numerical figures as well as questionnaires to collect data to obtain detailed information about the problem under investigation.

The target population for the study was employees working in organisations formed and established in the United Arab Emirates. The target population referred to the number of people from which data was collected and studied. As the target population is usually high, in the current study, the population was very large, so the study was based on a selection of samples from the whole population. According to the Ministry of Economy, a total number of 6,330,540 employees work in all organisations of the United Arab Emirates. Furthermore, according to the statistics released by the Federal Competitiveness and Statistics Authority, $2.33 \%$ of the total workforce work in Federal Government entities, $8.28 \%$ of the total workforce is working in the local governments and $4.67 \%$ of the total workforce work in the shared government (government and corporations combination) entities. From the above analysis, it was discovered that $15.28 \%$ of the total workforce $6,330,540$ was the target 
population for the purpose of current study. A table was referred to determine a suitable sample size which was presented by the Krejcie and Morgan (1970). The population size was between 500,000 and 1,000,000. Based on the confidence level and margin of error, the sample size was 384 number of sample participants.

The instrument used for the current research comprised of questionnaire with structured items related to employees' performances, workplace learning and organisational culture. The questionnaire was developed to capture the data from employees according to their perceptions of workplaces as learning environments and the impact on the performances. Three different adapted questionnaires were used to draft a new questionnaire according to the conditions and valid dimensions of variables. Validity and reliability of these dimensions were confirmed to get relevant dimensions of the problem under investigation. The questionnaire used in the study was based on items from different questionnaires, for examples, questionnaires of organisational culture (OC) as used by O'Reilly et al. In their study (1991), Hofstede et al., (1990 and Verbeke, (2001), second questionnaire of employees' work performances (Individual work performance Questionnaire - IWPQ) developed by Koopmans (2013) which had seven items for task performance, twelve items for contextual performance, and eight items for counterproductive work behaviour (total of 27 items) and questionnaire of workplace learning consisting of 17 items, as identified by Rowden (2002), was used in combination to check the impacts of desired hypothesis.

\section{Data Analysis and Results}

In the bid to obtain an empirical information on whether the independent variables: formal learning, informal learning and incidental learning, significantly affected the dependent variables: task performance, contextual performance and counterproductive work behaviour, the t-test was used to test the relevance and significance of the parameters of the independent variables to dependent variables. The first analysis was based on the basic hypothesis to determine the relationship between dependent and independent variables. The proposed model and hypothesis were tested using Smart PLS (partial least square). The figure provided below tested the basic hypothesis to determine the initial relationship between dependent and independent variables. As per path analysis, formal learning had statistically significant relationship with task performance $(\beta=0.429, \rho<0.05)$, and contextual performance $(\beta=$ $0.233, \rho<0.05)$ but insignificant relation with counterproductive work behaviour $(\beta=-0.033$, $\rho>0.05)$. This relationship was statistically significant at $5 \%$ level of significance. Basic analysis of relationship between variables revealed that Informal learning was statistically significantly related to task performance $(\beta=0.247, \rho<0.05)$, contextual performance $(\beta=$ 0.247, $\rho<0.05)$ and counterproductive work behaviour $(\beta=-0.240, \rho<0.05)$. This relationship was significant at $5 \%$ level of significance. Incidental learning was found to be insignificantly related to task performance $(\beta=-0.066, \rho>0.05)$, contextual performance $(\beta$ $=0.012, \rho>0.05)$ and counterproductive work behaviour $(\beta=-0.061, \rho>0.05)$.

\section{Innovation and task performance}

Statistical analysis of the model depicted that there was a significant relationship between formal learning and task performance $(\beta=0.429, \rho<0.05)$. However, this relationship iwas not moderated by the innovation culture of organisations in the United Arab Emirates. It was the same case which was observed in informal learning and incidental learning. Informal learning was significantly and positively related to the task performance $(\beta=0.246, \rho<0.05)$ 
but this relationship was not signified (made strong or weak) by the interaction term of innovation and Informal learning. Incidental learning was already found to be insignificantly related to the task performance $(\beta=-0.058, \rho>0.05)$. Furthermore, the moderation term of innovation and incidental learning had no impact on the relationship between task performance and incidental learning in organisations working in the United Arab Emirates.

\section{Innovation and contextual performance}

Statistical moderating analysis of the model depicts that there was a significant positive relationship between formal learning and contextual performance $(\beta=0.249, \rho<0.05)$. This relationship was moderated by the innovation culture of the organisations in the United Arab Emirates but a weak effect was found with moderation $(\beta=0.111, \rho<0.10)$. Therefore, the moderation effect was significant at $10 \%$ level of significance. Significant direct results were observed in case of informal learning and incidental learning with contextual performance. Informal learning was significantly and positively related to the contextual performance $(\beta=$ $0.221, \rho<0.05$ ) but this relationship was not moderated by the interaction term of innovation and informal learning $(\beta=0.117, \rho>0.05)$. Incidental learning was also found to be insignificantly and negatively related to the contextual performance $(\beta=-0.004, \rho<0.05)$. This relationship was also not moderated by the interaction term of innovation and incidental learning.

\section{Innovation and counterproductive behaviour}

The resulting model showed that there was a insignificant relationship between formal learning and counterproductive work behaviour of employees in the United Arab Emirates organisations $(\beta=-0.039, \rho>0.05)$ and the moderation of innovation culture was not proven to be significant in this relationship. Similar results were found in incidental learning and counterproductive behaviour. Although the relation between incidental learning and counterproductive work behaviour was negative but it was significant $(\beta=-0.061, \rho>0.05)$ and no moderation effects were found in this relationship as well. In case of informal learning and contextual performance, the relationship was negative and significant $(\beta=-0.232, \rho<$ $0.05)$. This relationship was made weak by the interaction term of innovation and Informal learning at $10 \%$ level of significance as the value of $\beta=-0.232$ had become $\beta=-0.093, \rho<$ 0.10 .

\section{People oriented culture and task performance}

The relationship between task performance and formal learning was significant and positive $(\beta=0.319, \rho<0.05)$ but this direct value of beta coefficient had reduced from 0.429 to 0.319 as compared to the previous model. People oriented culture was an interaction term between task performance and formal learning which made this relationship negative but significant. This meant that there was negative effect of moderation on task performance and formal learning $(\beta=-0.135, \rho>0.05)$. Similar results were observed with informal learning and task performance the beta coefficients were reduced from 0.247 to 0.182 but having statistically positive and significant relation at $5 \%$ level of confidence. This relationship was also significant with the moderation effect of people oriented culture $(\beta=0.131, \rho<0.05)$. Furthermore, it was observed that the relationship among the independent variable of incidental learning and dependent variable of task performance was neither directly significant nor in the presence of moderation effect of people oriented culture $(\beta=-0.025, \rho>0.05)$. 


\section{People oriented culture and contextual performance}

It was found that the relationship between the variable of formal learning and the variable of contextual performance was positive and statistically significant $(\beta=0.116, \rho<0.05)$ and the relationship was moderated to $\beta-0.128, \rho<0.10$. It means that the moderation had a negative impact on the original relationship between the level of formal learning and the variable of contextual performance. Now the relationship was significant at $10 \%$ level of significance and beta coefficient had decreased to a negative value. Informal learning and contextual performance were also positively and significantly related to each other $(\beta=0.180, \rho<0.05)$ but there was no moderation effect on this relationship as evident from $\beta=0.080, \rho>0.10$. Direct relation between incidental learning and contextual performance was insignificant and even moderation also did not have any effect on this relationship $(\beta=-0.007, \rho>0.05)$

\section{People oriented culture and counterproductive work behaviour}

The direct relationship between formal learning and incidental learning was found to be insignificant with counterproductive work behaviour which was evident from the coefficient values $\beta=0.094, \beta=-0.069$ and $\rho>0.05$ respectively. The moderation also did not have any significant impact on the direct relationship between variables. However, informal learning had direct and significant relationship with the counterproductive work behaviour $(\beta=-$ $0.159, \rho<0.05$ ). The moderation failed to provide any strong or weak impact on the relationship between these two variables and it was evident from the significance value of the relationship $\beta=-0.040, \rho>0.05$ and $\beta=-0.032, \rho>0.05$. Furthermore, the relationship between incidental learning was also insignificant and there was no moderation effect on this variable as evident from $\beta=0.066, \rho>0.05$

\section{Communication oriented culture and task performance}

The model in the study indicated that independent variables of formal learning and informal learning had positive and significant relationship with the task performance as evident from coefficient values $\beta=0.399, \rho<0.05$ and $\beta=0.252, \rho<0.05$. Conversely, there was no direct relationship between incidental learning and task performance as evident from $\beta=-0.053, \rho$ $>$ 0.05. As far as moderation was concerned, there was no effect of interaction term of communication on formal, informal and incidental learning with task performance.

\section{Communication oriented culture and contextual performance}

Formal learning and Informal learning had direct positive and significant relation with contextual performance which was evident from beta coefficients; $\beta=0.230, \rho<0.05$ and $\beta=$ $0.230, \rho<0.05$ respectively. Conversely, incidental learning had not significant relation with contextual performance in organisations in the United Arab Emirates. As far as moderation was concerned, formal learning and incidental learning had no moderation effects but in case of Informal learning, the value of beta coefficient was 0.140 and it was significant at $10 \%$ level of significance. The Informal learning and contextual performance was weak by the moderation effect of communication oriented culture of the organisations in the United Arab Emirates.

\section{Communication oriented culture and counterproductive work behaviour}


There was insignificant relationship between formal learning and counterproductive behaviour $(\beta=-0.02, \rho>0.05)$ and as far as moderation of communication culture was concerned, there was no moderation effect on this relationship as evident from $\rho$-values $(\rho>$ 0.05). Formal learning was negatively and significantly related to counterproductive work behaviour $(\beta=-0.232, \rho<0.05)$ and communication culture also had strong moderating effect on this relationship as the value of beta coefficient had increased to -0.119 from -0.232 and $\rho$ $<0.05$. It shows that the communication culture is playing moderating variable role in the relationship between Informal learning and counterproductive work behaviour. Incidental learning was found to be insignificant even in the presence of moderating variable.

Result oriented culture and task performance

The model results showed that formal learning was positively and significantly related to the task performance of the organisations in the United Arab Emirates $(\beta=0.401, \rho<0.05)$, Informal learning was positive and significant with $\beta=0.198, \rho<0.05$ and incidental learning was negative and significant with $\beta=-0.105, \rho<0.10$. Formal and Informal learning both were significant at 5\% level of significance whereas; the incidental learning was significant at $10 \%$ level of significance. As far as interaction term of result, formal learning result, informal learning and results and incidental learning are concerned, there was not even a single moderation found in this relationship.

Result oriented culture with contextual performance

As per results of the model, formal learning was positively related to contextual performance $(\beta=0.162, \rho<0.05)$ but this relationship was not moderated by the interaction term of result and formal learning $(\beta=-0.009, \rho>0.05)$. Informal learning was also positively related to the contextual performance $(\beta=0.151, \rho<0.05)$. Here, in this case the moderation had negative effects. It means that moderation had weakened the relationship which was evident from $\beta=$ $0.094, \rho<0.10$. This relationship was significant at $10 \%$ level of significance. Alternatively, the relationship between incidental learning and contextual performance was insignificant and moderation did not affect this relationship $(\beta=-0.040, \rho>0.05)$. Error! Reference source not found. shows the moderating effect of result oriented culture on contextual performance.

\section{Result oriented culture with counterproductive work behaviour}

The model results showed that there was a insignificant relationship between formal learning and counterproductive work behaviour as well as incidental learning and counterproductive work behaviour. This was evident from the coefficient and $\rho$-values which were $\beta=0.009, \rho>$ 0.05 and $\beta=-0.052, \rho>0.05$ respectively. As far as Informal learning was concerned, it was found to be a significant variable with relationship of counterproductive work behaviour $(\beta=$ - $0.209, \rho>0.05$ ). For moderation effects, there was not even a single relationship on which moderation had significant impact. Even the significant relationship between Informal learning and counterproductive work behaviour was made insignificant with interaction term of informal learning counterproductive work behaviour.

\section{Team oriented culture with task performance}

Formal learning was found to be statistically significant and positive relation with task performance in this model $(\beta=0.464, \rho<0.05)$ but this relationship was weak even insignificant by the interaction term of team culture formal learning $(\beta=-0.123, \rho>0.05)$. Informal learning, on the other hand, having positive and significant direct relation with task 
performance $(\beta=0.225, \rho<0.05)$ faced the same problem that moderation had made this relationship weak and insignificant $(\beta=0.060, \rho>0.05)$. In contrast to this, incidental learning was insignificant in the direct relation of task performance $(\beta=-0.050, \rho>0.05)$ but moderation effect of team culture had made it significant $(\beta=-0.143, \rho<0.05)$.

\section{Team oriented culture with contextual performance}

Formal and Informal learning were found to have significant and positive relationship with the contextual performance which was evident from the regression results $(\beta=0.287, \rho<$ $0.05)$ and $(\beta=0.203, \rho<0.05)$. On the other hand, incidental learning was found to be insignificant with the direct relation with the contextual performance of employees in UAE organisations $(\beta=-0.061, \rho>0.05)$. As far as moderation effect of team oriented culture was concerned, opposite pattern was observed in the results of the model. On one hand, moderation made the formal and Informal learning insignificant $(\beta=-0.135, \rho>0.05$ and $\beta=$ $0.003, \rho<0.05$ respectively) and on the other hand it made the incidental learning significant but with a weak coefficient value $(\beta=-0.166, \rho<0.05)$.

\section{Team oriented culture with counterproductive work behaviour}

Formal learning was found to have insignificant relationship with counterproductive work behaviour $(\beta=-0.030, \rho>0.05)$. This relationship was made significant by the team oriented interaction term * formal learning $(\beta=0.190, \rho<0.05)$. This relationship was made weak by the interaction term but still significant as compared to the direct relationship. Informal learning was found to have significant and negative direct relationship with the counterproductive work behaviour $(\beta=-0.191, \rho<0.05)$ but moderation term had made it insignificant $(\beta=-0.052, \rho>0.05)$. incidental learning on the other hand behaved differently as compared to formal and Informal learning with $\beta=-0.110, \rho<0.05$ and having strong moderation effects $\beta=0.167, \rho<0.05$. Error! Reference source not found. shows the moderating effect team oriented culture on counterproductive work behaviour.

\section{Conclusion}

It can be concluded that if an organisation is willing to improve the task performance and contextual performance of the employees, it is necessary to improve the formal learning. But, at the same time, the task performance will negatively impact the counter productive work behaviour of employees. The current paper also reviewed the literature available on the topic of workplace learning and the job performance including three different types of workplace learning: formal learning, informal learning and incidental learning with an impact on job performances including task performance, contextual performance and counterproductive workplace behaviour. Based on the current research, it can be concluded that the positive and directly significant relationship existed between the workplace learning and task performance and also between the workplace learning and the contextual performance. There was a positive but insignificant relationship between the workplace learning and counterproductive work behaviour. It is highly encouraged to conduct an empirical study to check the relationship and impact of workplace learning and organisational performance because it is the organisation that will gain advantage of any improved job performances. The study will also contribute towards the existing studies and literature of the human resource management and development theoretically. Furthermore, the current study will practically provide an insight to the management and governmental officials to set strategies of workplace learning in order to improve the performance of the employees. Based on the 
findings and results of the current research, appropriate policies and course of actions can be designed at appropriate level to improve performances of employees in the United Arab Emirates. The job designs can be enhanced and properly structured in order to provide opportunities of growth in the workplace through effective strategies of workplace place learning because it will improve the job performance of the employees.

\section{References}

[1] Aragon-Sanchez, A., Barba-Aragon, I., \& Sanz-Valle, R. (2003). Effects of training on business results. International Journal of Human Resource Management, 14(6), 956980.

[2] Barrie, J., \& Wayne Pace, R. (1998). Learning for organisational effectiveness: Philosophy of education and human resource development. Human Resource Development Quarterly, 9(1), 39-54.

[3] Bednall, T. C., Sanders, K., \& Runhaar, P. (2014). Stimulating Informal learning activities through perceptions of performance appraisal quality and human resource management system strength: A two-wave study. Academy of Management Learning \& Education, 13(1), 45-61.

[4] Borman, W. C., \& Motowidlo, S. J. (1993). Expanding the criterion domain to include elements of contextual performance. Personnel selection in organisations, 71, 98.

[5] Brown, J., \& Duguid, P. (2000). Organisational learning and communities of practice: Toward a unified view of working, learning, and innovation. In Knowledge and communities (pp. 99-121).

[6] Cairns, L., \& Malloch, M. (2011). Theories of work, place and learning: New directions. The Sage Handbook of Workplace Learning, 3-16.

[7] Campbell, J. P., McHenry, J. J., \& Wise, L. L. (1990). Modeling job performance in a population of jobs. Personnel Psychology, 43(2), 313-575.

[8] Colarelli, S. M., \&Montei, M. S. (1996). Some contextual influences on training utilization.The Journal of Applied Behavioural Science, 32(3), 306-322.

[9] Cromwell, S. E., \& Kolb, J. A. (2004). An examination of work-environment support factors affecting transfer of supervisory skills training to the workplace. Human Resource Development Quarterly, 15(4), 449-471.

[10] Daryoush, Y., Silong, A. D., Omar, Z., \& Othman, J. (2013). Improving job performance: Workplace learning is the first step. International Journal of Education \& Literacy Studies, 1(1), 100.

[11] Farouk, S., Abu Elanain, H. M., Obeidat, S. M., \& Al-Nahyan, M. (2016). HRM practices and organisational performance in the UAE banking sector: The mediating role of organisational innovation. International Journal of Productivity and Performance Management, 65(6), 773-791.

[12] Gilbert, T. F. (1978). Human competence-Engineering worthy performance. Nspi Journal, 17(9), 19-27.

[13] Heilmann, P. (2007). High level competence: a tool for coping with organisational change. Journal of European Industrial Training, 31(9), 727-741.

[14] Jacobs, R. L., \& Park, Y. (2009). A proposed conceptual framework of workplace learning: Implications for theory development and research in human resource development. Human Resource Development Review, 8(2), 133.

[15] Jiménez-Jiménez, D., \& Sanz-Valle, R. (2011). Innovation, organisational learning, and performance. Journal of Business Research, 64(4), 408-417. 
[16] Jones, R. J., Woods, S. A., \& Guillaume, Y. R. (2016). The effectiveness of workplace coaching: A meta-analysis of learning and performance outcomes from coaching. Journal of Occupational and Organisational Psychology, 89(2), 249-277.

[17] Joo, B. K., \& Ready, K. J. (2012). Career satisfaction: The influences of proactive personality, performance goal orientation, organisational learning culture, and leader-member exchange quality. Career Development International, 17(3), 276-295.

[18] Koopmans, L. (2013). 51 Improving the individual work performance questionnaire using rasch analysis. Occup Environ Med, 70(Suppl 1), A17-A18.

[19] Lin, W. B. (2008). The effect of knowledge sharing model. Expert Systems with Applications, 34(2), 1508-1521

[20] Marsick, V. J., \& Volpe, M. (1999). The nature and need for Informal learning. Advances in Developing Human Resources, 1(3), 1-9.

[21] Marsick, V. J., \& Watkins, K. (2015). Informal and Incidental Learning in the Workplace (Routledge Revivals). Routledge.

[22] Meyer, J. P., \& Allen, N. J. (1991). A three-component conceptualization of organisational commitment. Human Resource Management Review, 1(1), 61-89.

[23] Moon, S. Y., \& Na, S. I. (2009). Psychological and organisational variables associated with workplace learning in small and medium manufacturing businesses in Korea. Asia Pacific Education Review, 10(3), 327-336.

[24] Motowildo, S. J., Borman, W. C., \& Schmit, M. J. (1997). A theory of individual differences in task and contextual performance. Human Performance, 10(2), 71-83.

[25] Nadler, L. (1970). Developing human resources.

[26] O'Reilly III, C. A. (1991). Organisational behaviour: Where we've been, where we're going. Annual Review of Psychology, 42(1), 427-458.

[27] Pajo, K., Coetzer, A., \& Guenole, N. (2010). Formal Development Opportunities and Withdrawal Behaviours by Employees in Small and Medium-Sized Enterprises. Journal of Small Business Management, 48(3), 281-301.

[28] Rothwell, W. J. (2002). Putting success into your succession planning. Journal of Business Strategy, 23(3), 32-37.

[29] Schein, Edgar H. Organisational Culture and Leadership. San Francisco: Jossey-Bass, 2010. Print.

[30] Shuck, B., Ghosh, R., Zigarmi, D., \& Nimon, K. (2013). The jingle jangle of employee engagement: Further exploration of the emerging construct and implications for workplace learning and performance. Human Resource Development Review, 12(1), 11-35.

[31] Tai, W. T. (2006). Effects of training framing, general self-efficacy and training motivation on trainees' training effectiveness. Personnel Review, 35(1), 51-65.

[32] Van Dyne, L., \& LePine, J. A. (1998). Helping and voice extra-role behaviours: Evidence of construct and predictive validity. Academy of Management Journal, 41(1), 108-119.

[33] Watkins, K. E., \& Marsick, V. J. (1992). Towards a theory of informal and incidental learning in organisationsâ^-. International Journal of Lifelong Education, 11(4), 287300. 